Received: August 11, 2017

Revision received: June 2,2018

\title{
Research on Effectiveness Analysis and Evaluation of Sports Innovation Course Teaching
}

\author{
Songfeng $\mathrm{Li}^{1}$ \\ Hebei Agricultural University \\ Haizhe Zhang ${ }^{3}$ \\ Baoding University
}

\author{
Li Zhen ${ }^{2}$ \\ Hebei Agricultural University \\ Jianlong $\mathrm{Ma}^{4}$ \\ Hebei Agricultural University
}

\begin{abstract}
The practice of sports teaching is the main direction and foundation of the effectiveness of sports innovation course teaching, and it is also the process of arranging, testing and guiding teaching in the course of teaching. However, at present, it is still urgent to solve the effectiveness analysis and quality evaluation of sports teaching innovation. In the teaching work and practice of sports teaching innovation, a great deal of practical data information needs to be stored, researched and analyzed. In the face of huge data estimation and understanding, it is common to use manual processing at present, resulting in the poor expression and availability of these data. This paper is aimed at how to make use of the large amount of data produced in the teaching practice efficiently and reasonably, and puts forward a research model of effectiveness analysis and teaching quality evaluation of innovative teaching of sports based on the idea of large data mining. It has been proved to be feasible and scientific in the teaching practice.
\end{abstract}

\section{Keywords}

Sports Teaching • Teaching Innovation • Teaching Quality Evaluation • Teaching Effectiveness Analysis • Data Mining

\footnotetext{
${ }^{1}$ Department of Sports Works, Hebei Agricultural University, Baoding 071000, China. Email: 326911945@qq.com ${ }^{2}$ Department of Sports Works, Hebei Agricultural University, Baoding 071000, China. Email: 77468010@qq.com ${ }^{3}$ Institute of Physical Education, Baoding University, Baoding 071001, China. Email: zhz121100@163.com ${ }^{4}$ Correspondence to: Jianlong Ma, Department of Sports Works, Hebei Agricultural University, Baoding 071000, China. Email: mayongqing05@126.com
}

Citation: Li, S. F., Zhen, L., Zhang, H. Z., \& Ma, J. L. (2018). Research on Effectiveness Analysis and Evaluation of
Sports Innovation Course Teaching. Educational Sciences: Theory \& Practice, 18(5), 2247-2253.
http://dx.doi.org/10.12738/estp.2018.5.123


Teaching effectiveness analysis and teaching quality evaluation aim at education and teaching to achieve the practical value of evaluation. This is a dynamic process (Speck, Ruzhitskaya, \&, Whittington, 2012). The effectiveness analysis of teaching and the evaluation of teaching quality need to be intuitively understood with predetermined goals. The object of evaluation is all the teaching activities covering all the processes and actual effects (Abrami et al., 2014). Intuitive thinking is a reasonable assessment of the possible impact of teaching activities, to further change and develop teaching activities, constantly improve the educational management system and ensure the effectiveness and advantages of the teaching (Tireneh, Cock, Weldeslassie, Elen, \& Janssen, 2016; Paasonen et al., 2014).

At present, many colleges and universities have begun to innovative course teaching of sports, and made analysis and evaluation of teaching effectiveness and quality. The analysis and evaluation of teaching effectiveness and teaching quality include the following aspects: evaluation method, evaluation organization, evaluation index, evaluation statistics management, and feedback on the evaluation results (William, et al., 2011; Notebaert, \& Guskiewicz, 2015). In some colleges and universities, it is common to use executive analysis, peer assessment, student assessment, and self-assessment (Fraas, Coughlan, Hart, \& Mccarthy, 2014). The vice principal of a university is always responsible for the evaluation of the teaching quality and Dean's Office is responsible for the actual operation, with a teaching quality assessment committee established. Assessment data statistics and management are usually based on student assessment, peer assessment, selfassessment and unified outcome of supervisor assessment (Quarrie et al., 2016; Grindel, Lovell, \& Collins, 2011). However, the depth and breadth of the statistic and management of the above-mentioned evaluation data are insufficient (Lynall, Laudner, Mihalik, \& Stanek, 2013), and the strong effectiveness of the data generated in the teaching practice is not fully exerted, without accurate analysis and evaluation of the teaching effectiveness and quality.

This paper first analyzes and studies the effectiveness and quality of the teaching practice of sports innovation course, analyzes the development trend of teaching quality evaluation, and then applies data mining technology in the evaluation of teaching effectiveness and quality to describe the three main steps of data mining application in teaching effectiveness and quality evaluation. Finally, the paper constructs the teaching effectiveness and quality evaluation system and model of sports innovation course based on data mining by means of analytic hierarchy process. At the same time, this paper discusses the feasibility and scientificity of the teaching effectiveness and quality evaluation system and the model in the two aspects of learning evaluation and classroom teaching evaluation.

\section{Analysis on Teaching Effectiveness and Evaluation Trend of Sports Innovation Course}

The analysis and evaluation of teaching effectiveness and teaching quality of innovative course in sports includes not only teaching attitude, teaching content, using method and practical effect, but also a teacher's communication skills and overall level. The evaluation results feedback is usually communicated through the 
Dean's Office and then sent to the teacher, while the results are reported to the management for further decisionmaking and teacher management.

More and more attention has been paid to the analysis and evaluation of teaching effectiveness and quality in the sports innovative course in every university. At present, the analysis and evaluation of teaching effectiveness and quality in most colleges and universities have the following trends.

The first trend, teaching content generalizes teaching effectiveness and quality evaluation. In the long run, the evaluation of the innovative teaching effectiveness and quality of sports course in colleges and universities are the potential to guide degrees and themselves to be influenced by normal teaching methods. Moreover, the evaluation of teaching effectiveness is usually based on student test results. This method ignores the students' mastery of relevant skills, practical teaching effect and teaching ability. Therefore, the evaluation of teaching effectiveness and quality of teaching innovation course has drawn more and more attention from researchers and professionals.

The second trend is the variation of teaching effectiveness evaluation methods. Due to the limitations of innovative teaching methods and teaching practice evaluation methods, there is no perfect method for evaluating the effectiveness and quality of each teaching work. In practical work practice, each analysis and evaluation method has its own advantages and disadvantages, with limited scope of use. In order to ensure the evaluation of teaching effectiveness and quality, an organic and unified comprehensive evaluation method of quantity and quality is put forward by rational and intuitive education. During the evaluation period, the evaluator and the evaluated person evaluate the progress. This can facilitate the development of each evaluation without inconvenience and with greater rationality and effectiveness.

The third trend is the diversification of teaching effectiveness and quality evaluation. The important feature of innovative course teaching in sports is the subject of multidisciplinary evaluation. This means that the simple teaching department is transformed into the cooperation of managers and peer teachers, and the society, students and teachers can evaluate more comprehensively and objectively. Students and teachers are the main objects of teaching evaluation.

\section{Application of Data Mining in the Analysis and Research of Innovative Course Teaching Effectiveness}

There are different interpretations of data mining from its emergence to the present. Generally speaking, data mining is the capture and induction of a large amount of data. Data mining is like gold washed from the sand, so it is also known as gold mine. Usama M. Fayyad and other partners summed up the data mining industry. Data mining filters out unobvious, unknown, and useful knowledge from huge amounts of data. Although these messages are unknown, they are valuable for mining. The current data mining is summarized through the function. Data mining is the process of searching for interesting rules through a large number of data messages. Data mining is the integration of various advanced technologies, including the application of database, database technology, statistics, machine learning, mathematical statistics, neural network and other related interdisciplinary branches with expansibility. 
Li, Zhen, Zhang, Ma / Research on Effectiveness Analysis and Evaluation of Sports Innovation Course Teaching.

The process of data mining is divided into three steps. First, collect and pre-process the data. Then, the data mining method is used to model the pre-processed data. Combining with the teaching practice of sports innovation course, this paper introduces in detail the process of data analysis on the teaching effectiveness and quality of sports innovation course based on data mining.

Step 1: Collect and pre-process the data. The data such as student achievement data, teacher classroom teaching achievement data, and so on can be extracted from the database of relevant management departments in colleges and universities. After the raw data is obtained, noise data, vacancy data and inconsistent data contained in the data are removed by using the data preprocessing technology, and the processed data is cleaned, integrated and converted to obtain the data storage form which can be directly mined.

Step 2: Data modeling. By using the correlation analysis algorithm in data mining, this paper explores the correlation between the students' examination results and the unknown factors such as students' personal information, professional orientation, teachers' information and so on. The clustering algorithm is used to analyze the student's achievement data, and to observe the useful information reflected by the student's achievement from various angles. This paper uses the classification algorithm to extract and mine the relationship between the median value of each teacher's classroom teaching achievement and teacher's quality, student's quality, scoring index setting, weight setting and students' examination result.

Step 3: Explain the model. Solving different problems and forms with different data mining algorithms are the results of different mining, such as decision tree classification algorithm based on decision tree mining model is not a problem for data miners, but cannot manage actual fields, so it's necessary to convert a decision tree into text information that can be understood. The results of these interpretation mining will provide a basis for decision-making that directly assists teachers and management decision-makers.

\section{Evaluation Model of Sports Innovation Course Teaching}

The analytical hierarchy process is a flexible, practical and simple multi-criteria decision analysis method. The basic idea of analytical hierarchy process is to decompose a complex problem into layers and then transform it into a quantitative analysis method. This method needs to establish the structure attribute of each factor that affects the system, then compare the factors in each level, obtain the judgment matrix and the relative weight of the previous hierarchy factor, and finally calculate the final value of the importance of each factor.

In the teaching practice of sports innovative course, the evaluation of teaching effectiveness and quality is also a multi-index and multi-level evaluation problem. In the process of teaching effectiveness and quality evaluation, it's essential to consider the influence of various factors as well as the selection of various factors at various levels, integrate the factors with similar influence result, take into account the distribution and representativeness of influence factors, and add weighted weights to calculate the final value of each influencing factor.

Based on the analysis of the factors of evaluating effectiveness and quality of the sports innovative course, combining with the algorithm for weighting the various levels of the model in the above-mentioned analytic 
Li, Zhen, Zhang, Ma / Research on Effectiveness Analysis and Evaluation of Sports Innovation Course Teaching.

hierarchy process, this paper calculates the weights of the factors of each level in effectiveness and quality evaluation.

First, the weight coefficient of the overall indexes of teaching quality is calculated. The factors such as specialty and course construction, teachers' team, teaching conditions, teaching effect, teaching organization and management are the main factors that affect the teaching effectiveness and quality of educational innovation course. In order to calculate the weight coefficient of the overall indexes of the teaching effectiveness and quality of sports innovation, firstly, the relative importance of the above factors that affect the effectiveness and quality of sports innovation teaching should be compared to judge their relationship with the overall level of teaching quality, that's, the relative importance to the effectiveness and quality of sports innovation teaching. According to the ratio of relative importance of indexes determined, the judgment matrix of effectiveness and quality evaluation system of sports innovation teaching is constructed, as shown in the following table.

Table 1

Evaluation Index Judgment Matrix of Sports Innovative Teaching

\begin{tabular}{lccccc}
\hline & $\begin{array}{c}\text { Curriculum } \\
\text { development }\end{array}$ & $\begin{array}{c}\text { Teacher } \\
\text { training }\end{array}$ & $\begin{array}{c}\text { Teaching } \\
\text { conditions }\end{array}$ & $\begin{array}{c}\text { Teaching } \\
\text { organization }\end{array}$ & $\begin{array}{c}\text { Teaching } \\
\text { effect }\end{array}$ \\
\hline Curriculum development & 1 & $1 / 2$ & 3 & 2 & $1 / 3$ \\
Teacher training & 3 & 1 & 5 & 4 & 2 \\
Teaching conditions & $1 / 2$ & $1 / 4$ & 1 & $1 / 5$ & $1 / 3$ \\
Teaching organization & 2 & $1 / 2$ & 5 & 1 & 4 \\
Teaching effect & $1 / 3$ & $1 / 5$ & 3 & $1 / 4$ & 1 \\
\hline
\end{tabular}

Then, taking classroom teaching quality evaluation as an example, the weight coefficient of each index is calculated. Based on the analysis of the hierarchy diagram of effectiveness and quality evaluation of sports innovation teaching, the importance value of each index in the criterion level with respect to target level in the hierarchy of effectiveness and quality evaluation of sports innovation teaching is determined, so as to construct the evaluation index judgment matrix of effectiveness and quality evaluation of physical education innovation teaching.

In the end, accord to the relationship between the scheme level and the criterion level in the hierarchy of the effectiveness and quality evaluation of sports innovation teaching, the relative importance degree of each scheme relative to the specific goal is determined to construct the evaluation index judgment matrix of effectiveness and quality evaluation of sports innovation teaching. During the effectiveness and quality evaluation of sports innovation teaching, there are four indexes to evaluate the teaching method: student evaluation, expert evaluation, peer teacher evaluation and teaching assistant evaluation. The matrix shown in the following table can be established by comparing the relative importance of the evaluation results of teaching methods by each evaluator.

Table 2

Sports Innovation Teaching Effectiveness Evaluation Teaching Method Evaluation Judgment Matrix

\begin{tabular}{lcccc}
\hline Evaluation index & $\begin{array}{c}\text { Student } \\
\text { evaluation }\end{array}$ & $\begin{array}{c}\text { Expert } \\
\text { evaluation }\end{array}$ & $\begin{array}{c}\text { Peer } \\
\text { evaluation }\end{array}$ & $\begin{array}{c}\text { Supplementary } \\
\text { evaluation }\end{array}$ \\
\hline Student evaluation & 1 & $1 / 2$ & $1 / 3$ & $1 / 4$ \\
Expert evaluation & 2 & 1 & $1 / 4$ & $1 / 2$ \\
Peer evaluation & 3 & 4 & 1 & 2 \\
Supplementary evaluation & 2 & 3 & $1 / 3$ & 1 \\
\hline
\end{tabular}


Based on the data mining technology, the effectiveness and quality evaluation of sports innovation teaching can be made into a software system module, which mainly completes the data collection of the effectiveness and quality evaluation of sports innovation teaching. Each evaluation participant can complete the evaluation of the effectiveness and quality of the sports innovation teaching through the evaluation module corresponding to the evaluation system, and input the evaluation result data into the database so as to provide data support for the next evaluation. The main function of the management module of effectiveness and quality of sports innovation teaching is to analyze and process the evaluation data, and it is composed of the evaluation and processing module and data mining module of sports innovation teaching. The evaluation and processing module is mainly used to analyze and collate the evaluation data of sports innovation teaching, and to calculate and solve the evaluation results, and it is the most important part of the quality evaluation of sports innovation teaching. Through the calculation of this module, we can get the result of the quality evaluation of sports innovation teaching.

The data mining module mainly aims at the potential data information in the existing database, and carries on the data mining and the comprehensive analysis in combination with the sports innovation teaching quality evaluation result. The main function of the sports innovation teaching quality inquiry module is the feedback of evaluation information, which is used for the inquiry of the evaluation result of sports innovation teaching quality by sports innovation teaching related personnel. For different inquirers, the system will design different inquiry authorities, including management decision-maker's inquiry of evaluation result, teacher's inquiry of evaluation result, and student's inquiry of evaluation result.

\section{Concluding Remarks}

On the basis of in-depth analysis and research on the teaching effectiveness and quality of sports innovation course, this paper analyzes the development trend of sports innovation teaching effectiveness and quality evaluation. This paper introduces data mining technology into teaching effectiveness and teaching quality evaluation, and expounds three steps of data mining application in teaching effectiveness and quality evaluation. Finally, the paper constructs the teaching effectiveness and quality evaluation system and model of sports innovation course based on data mining by means of analytic hierarchy process. From the aspects of learning evaluation and classroom teaching evaluation, this paper discusses feasibility and scientificity of the teaching effectiveness and quality evaluation system and model based on data mining, with a certain popularization potential.

\section{References}

Abrami, P. C., Bernard, R. M., Borokhovski, E., Wade, A., Surkes, M. A., \& Tamim, R. (2012). Instructional interventions affecting critical thinking skills and dispositions: A stage 1 meta-analysis. Review of Educational Research, 78(4), 1102-1134. http://dx.doi.org/10.3102/0034654308326084 
$\overline{\text { Fraas, M. R., Coughlan, G. F., Hart, E. C., \& Mccarthy, C. (2015). Concussion knowledge and management }}$ practices among coaches and medical staff in Irish professional rugby teams. Irish Journal of Medical Science, 184(2), 1-6. http://dx.doi.org/10.1007/s11845-014-1137-9

Grindel, S. H., Lovell, M. R., \& Collins, M. W. (2011). The assessment of sport-related concussion: The evidence behind neuropsychological testing and management. Clinical Journal of Sport Medicine, 11(3), 134-143. http://dx.doi.org/10.1097/00042752-200107000-00003

Lynall, R. C., Laudner, K. G., Mihalik, J. P., \& Stanek, J. M. (2013). Concussion-assessment and -management techniques used by athletic trainers. Journal of Athletic Training, 48(6), 844-850.

Notebaert, A. J., \& Guskiewicz, K. M. (2015). Current trends in athletic training practice for concussion assessment and management. Journal of Athletic Training, 40(4), 320-325. http://dx.doi.org/10.1152/japplphysiol.00563.2005

Paasonen, P., Nieminen, T., Asmi, E., Manninen, H. E., Petäjä, T., \& Plassdülmer, C. (2014). On the roles of sulphuric acid and low-volatility organic vapours in, the initial steps of atmospheric new particle formation. Atmospheric Chemistry and Physics, 10(5), 11223-11242. http://dx.doi.org/10.5194/acp-10-11223-2010

Quarrie, K. L., Raftery, M., Blackie, J., Cook, C. J., Fuller, C. W., \& Gabbett, T. J. (2016). Managing player load in professional rugby union: A review of current knowledge and practices. British Journal of Sports Medicine, 51(5), 91-96. http://dx.doi.org/10.1136/bjsports-2016-096191

Speck, A., Ruzhitskaya, L., \& Whittington, A. G. (2014). Assessment of teaching methods and critical thinking in a course for science majors. American Astronomical Society Meeting, 24(3-4), 223.

Tiruneh, D. T., Cock, M. D., Weldeslassie, A. G., Elen, J., \& Janssen, R. (2016). Measuring critical thinking in physics: Development and validation of a critical thinking test in electricity and magnetism. International Journal of Science \& Mathematics Education, 15(4), 1-20. http://dx.doi.org/10.1007/s10763-016-9723-0

William, A. E., Aguilarroca, N. M., Tsai, M., Wong, M., Beaupré, M. M., \& O’Dowd, D. K. (2011). Assessment of learning gains associated with independent exam analysis in introductory biology. CBE Life Sciences Education, 10(4), 346-356. http://dx.doi.org/10.1187/cbe.11-03-0025 